\title{
Linalool protects hippocampal CAl neurons and improves functional outcomes following experimental ischemia/reperfusion in rats
}

\author{
Vishal Airao, Prakruti Buch, Tejas Sharma, Devendra Vaishnav, Sachin Parmar* \\ Department of Pharmaceutical Sciences, Saurashtra University, Rajkot, Gujarat, India.
}

ARTICLE INFO

Article history:

Received on: November 04, 2020

Accepted on: December 25, 2020

Available online: March 14, 2021

\section{Key words:}

Anti-ischemic,

Antioxidant,

Cerebral injury,

Linalool,

Neuroprotective,

Oxi- and nitro-dative stress.

\begin{abstract}
Developing countries have witnessed a considerable surge in stroke incidence. In the wake of effective neuroprotective therapies, natural antioxidants offer a promising area for neuroprotection research. In this context, we investigated the neuroprotective efficacy of linalool (LIN) against transient ischemia $(30 \mathrm{~min}) /$ reperfusion (7 days) (I/R)-induced brain injury in Wistar albino rats. The oxidative stress enzymatic and non-enzymatic markers were estimated along with behavioral, infarction size, and histopathological evaluations. I/R injury significantly elevated lipid peroxidation (LPO), xanthine oxidase (XO), and nitric oxide (NO), and downregulated protective mechanisms such as superoxide dismutase (SOD), catalase (CAT), reduced glutathione (GSH), and total tissue sulfhydryl (T-SH) levels in rat brain. I/R injury produced significant infarction and hippocampal CA1 neuronal death. Further, LIN-treatment, that is, 25, 50, and $100 \mathrm{mg} / \mathrm{kg}$ for 1 month (p.o.) significantly enhanced the functional recovery of various neurobehavioral impairments induced by I/R. LIN-treatment also markedly reduced LPO, NO, and XO levels, and significantly improved SOD, CAT, GSH, and T-SH levels. Histopathological and coronal sectioning studies revealed LIN-treatment protected hippocampal CA1 neurons and reduced infarction. The findings of this study indicated that LIN-treatment augmented the antioxidant defense after I/R injury, and showed neuroprotective potential through its antioxidant activity in experimental rats.
\end{abstract}

\section{INTRODUCTION}

Among the cerebrovascular diseases, stroke accounts for $47-67 \%$ a considerable proportion of disability-adjusted life years and caused 5.5 million deaths in 2016 [1,2]. Ischemic stroke (IS) is the preliminary manifestation of acute cerebral ischemia and is often followed by a recurrent stroke. The Global Burden of Disease 2016 study reported a lifetime stroke risk of $24.9 \%$ in individuals aged $\geq 25$ years [3].

The brain is an immensely perfused organ that requires $25 \%$ body's total blood supply. Hence, any blood flow interruption results in oxygen and glucose supply disruption in the brain, especially when the hypoxic condition lasts for more than $5 \mathrm{~min}$. Thus, leading to a complex interplay of events including oxidative stress that causes neuronal injury and death within the brain, specifically the hippocampal neurons are more vulnerable and causes learning and memory neurological deficits $[4,5]$. It is also wellknown that ischemia/reperfusion (I/R) injury gives rise to the generation of reactive oxygen species (ROS) such as hydroxyl radical, superoxide $\left(\mathrm{O}_{2} \bullet-\right)$, hydrogen peroxide $\left(\mathrm{H}_{2} \mathrm{O}_{2}\right)$, and peroxynitrite radicals, which produce oxidative stress and play an important role in brain damage $[4,5]$.

Further, an enzymatic antioxidant such as superoxide dismutase (SOD) and non-enzymatic components including glutathione

*Corresponding Author:

Sachin Parmar, Department of Pharmaceutical Sciences,

Saurashtra University, Rajkot, Gujarat, India.

E-mail: parmarsachin@rediffmail.com balanced this generation of ROS [6]. Recently, edaravone, a neuroprotective antioxidant molecule, was approved to treat IS in Japan. Edaravone demonstrated beneficial effects on functional impairments, infarction volume, and hippocampal neuron protection following the I/R injury [7]. Moreover, recombinant tissue-type plasminogen activator is the only approved therapy for stroke that works the best if given within the 3-h window of stroke onset. However, it has side-effects such as cerebral hemorrhages and bleeding [8]. In recent years, more focus is being implemented on the use of alternative and natural medicine for the management of stroke. Phytoconstituents such as curcumin and resveratrol have been revealed to exhibit promising neuroprotective effects in the various stroke models [9]. In this particular study, we employed the global model of I/R injury, which is a well-established experimental model to simulate stroke conditions $[4,5]$.

(-)-Linalool (LIN), a major volatile monoterpene, is abundantly present in various aromatic plant spices [10]. LIN possesses varied pharmacological activities such as antidepressant, antianxiety, antiinflammatory, antioxidant, and anti-Alzheimer. Further, several studies reported the antioxidant activity of LIN could benefit the central nervous system functioning $[11,12]$. However, the neuroprotective role of LIN in transient cerebral ischemia has yet to be unexplored [13]. With this background, we aimed to assess the protective effect of LIN against oxidative stress and neuronal damage produced by cerebral I/R injury in experimental rats.

(C) 2021 Airao, et al. This is an open access article distributed under the terms of the Creative Commons Attribution License -NonCommercial-ShareAlike

Unported License (http://creativecommons.org/licenses/by-nc-sa/3.0/). 


\section{MATERIALS AND METHODS}

\subsection{Animals}

Healthy (150-250 g; 8 weeks) Wistar albino male rats from the central animal house of the institute were utilized for the current study. The rats were kept as four rats per cage (polypropylene) and acclimatized (1 week) before the execution of the protocol. The rats were maintained under standard animal housing conditions following the National Guidelines set by the Animal Welfare Division, Government of India. The experimental protocol was approved (IAEC/DPS/SU/1523).

\subsection{Experimental Design}

Rats were divided into six experimental groups $(n=12)$, including normal, sham, disease control (I/R), and three groups with LIN (SigmaAldrich, USA) treatment $(25,50$, and $100 \mathrm{mg} / \mathrm{kg} /$ day $)$. The drug or vehicle (normal saline solution containing $1 \%$ tween 80 ) treatments were administered orally ( $10 \mathrm{ml} / \mathrm{kg}$; per os $)$ for 1 month before surgery and continued for 7 days post-surgery [Figure 1]. The study was designed to make use of the least possible numbers of animals.

\subsection{Induction of Global Model of Ischemia}

The global model of cerebral ischemia was induced as per the method described elsewhere [14]. In brief, the animals were anesthetized (ketamine- $45 \mathrm{mg} / \mathrm{kg}$ and xylazine- $10 \mathrm{mg} / \mathrm{kg}$; i.p.) and placed on the back for the surgical procedure. A $2 \mathrm{~cm}$ cut was placed in the neck region (ventral position) after local disinfection with $70 \%$ alcohol and povidone-iodine cream. After that, bilateral common carotid arteries (BCCA) were disclosed, precisely detached from the vagus nerve, and occluded (30 min) with the help of a clamp (atraumatic) which lead to global cerebral ischemia. Immediately after $30 \mathrm{~min}$, occlusion was released to allow reperfusion for seven days in disease control and LINtreated groups. Further, the same surgical procedures were performed in the sham-operated animals except for BCCA-occlusion. All the surgical procedures were carried out in our laboratory under well-controlled conditions $\left(37 \pm 0.5^{\circ} \mathrm{C}\right.$ - temperature; $95 \% \mathrm{O}_{2}$ and $5 \% \mathrm{CO}_{2}$ - artificial ventilation).

\subsection{Neurobehavioral Functional Outcome Assessments}

The single evaluator performed all the behavioral assessments throughout the protocol.

\subsubsection{Neurological deficits}

The method developed by Lawner et al. was used to calculate the neurological score by adding the score of diverse clinical signs of ischemia after the completion of seven days of reperfusion [15].

\subsubsection{Rotarod}

The motor coordination and balance alterations were assessed using a rotarod apparatus [16]. In brief, each rat received a baseline trial 1 day before the assessment on accelerating rotarod with an increment of spindle speed from 4 to $40 \mathrm{rpm}$ for $3 \mathrm{~min}$. The latency to drop-off (in seconds) from the circling rod for each rat within 3 min was recorded as the incidence of ataxia.

\subsubsection{Open field paradigm}

The open-field comprising of a wood box (Square: $61 \mathrm{~cm} \times 61 \mathrm{~cm}$ ) with high walls $(61 \mathrm{~cm})$ was used to evaluate exploratory behavior. Individual exposure of $5 \mathrm{~min}$ was given to all rats by placing them in the center of the apparatus. The rats were observed for the ambulations, the number of rearings, and grooming [17].

\subsubsection{Elevated plus-maze}

The method adopted by Soares et al. was used to perform an elevated plus-maze (EPM) test and calculate anxiety-related behavior such as the percentage of entries in open arms and time consumed on the open arms (\% OAE and \%OT, respectively) [18].

\subsection{Post-mitochondrial Supernatant (PMS) Preparation}

Rats were anesthetized and decapitated immediately after 7 days of reperfusion using the overdose of thiopentone sodium. The brains were removed rapidly and washed in ice-cold saline solution. Subsequently, the brain was blotted on filter paper, weighed, and homogenated $10 \%$ $(\mathrm{w} / \mathrm{v})$ in chilled phosphate buffer $(0.05 \mathrm{M}, \mathrm{pH} 7.4)$. The homogenates were centrifuged $\left(10,000 \times g, 10 \mathrm{~min}, 4^{\circ} \mathrm{C}\right.$; MPW-350R, Korea), and the PMS was collected and kept in the deep freeze until assayed (UV 1800, Shimadzu, Japan).

\subsection{Biochemical Estimation}

\subsubsection{Lipid peroxidation (LPO)}

Braughler et al. described the method for the estimation of thiobarbituric acid reactive substances (TBRAS), an LPO marker in brain tissues [19]. Briefly, for $15 \mathrm{~min}$, the mixture containing $0.375 \%$ 2-thiobarbituric acid (TBA; Sigma-Aldrich, USA), 15\% trichloroacetic acid (TCA; Sigma-Aldrich, USA), and $5 \mathrm{~N} \mathrm{HCl}$ with brain homogenate was incubated at $95^{\circ} \mathrm{C}$. After that, it was cooled and centrifuged to collect the supernatant. With the help of an appropriate blank, absorbance was taken at $512 \mathrm{~nm}$. The amount of LPO (TBARS nmol/mg of protein) was determined using $\mathrm{e}=1.56 \times 10^{5} \mathrm{M}^{-1} \mathrm{~cm}^{-1}$ formula.

\subsection{2. $S O D$}

The protocol adopted by Misra and Fridovich was used to evaluate the SOD activity [20]. In particular, a mixture comprising $0.1 \mathrm{mM}$ epinephrine (Sigma-Aldrich, USA) in carbonate buffer ( $\mathrm{pH}$ 10.2) was added to the PMS, and absorbance was taken at $295 \mathrm{~nm}$. The standard plot of SOD was taken and the SOD activity was calculated. The SOD activity was expressed as U/mg of protein.

\subsubsection{Catalase (CAT)}

The assay was carried out by adding PMS $(10 \% \mathrm{w} / \mathrm{v}), \mathrm{H}_{2} \mathrm{O}_{2}(0.019 \mathrm{M})$, and phosphate buffer $(0.05 \mathrm{M}, \mathrm{pH} 7.0)$. Then, the absorbance changes for CAT $(240 \mathrm{~nm})$ were measured and represented as $\mathrm{nM} \mathrm{H}_{2} \mathrm{O}_{2}$ consumed $/ \mathrm{min} / \mathrm{mg}$ of protein [21].

\subsubsection{Total thiols}

The key principle behind the determination of the total thiols levels in the tissue homogenates is the formation of a relatively stable yellow color with the reaction between sulfhydryl groups and 5-5-dithiobis (2-nitrobenzoic acid) (DTNB; Sigma-Aldrich, USA) [22]. In brief, the assay solution was prepared by mixing PMS $(10 \% \mathrm{w} / \mathrm{v})$, phosphate buffer $(\mathrm{pH} 8)$, and $10 \mathrm{mM}$ DTNB and methanol. Then, the absorbance was taken after completion of 10 min incubation at $412 \mathrm{~nm}$ using an appropriate blank. The formula $\mathrm{e}=$ $13.6 \times 10^{31} \mathrm{~cm}^{-1} \mathrm{M}^{-1}$ was used to calculate the content of total thiol.

\subsubsection{Glutathione}

The method described by Sedlak and Lindsay was used to measure glutathione (GSH; Sigma-Aldrich, USA) [22]. Briefly, 20 mM EDTA (pH 4.7) was added to brain homogenate $(10 \% \mathrm{w} / \mathrm{v})$. Then, this mixture or pure GSH was further added in the $0.2 \mathrm{M}$ tris-EDTA buffer ( $\mathrm{pH} 8.2$ ), $20 \mathrm{mM}$ EDTA (pH 4.7), and $10 \mathrm{mM}$ DTNB in methanol (Ellman's reagent). After that, this assay mixture was kept for $30 \mathrm{~min}$ incubation at room temperature. After incubation completion, the test samples were centrifuged, collected supernatants, and the absorbance was taken at $412 \mathrm{~nm}$. 


\subsubsection{Determination of nitric oxide (NO) metabolites}

Miranda et al. defined the method for the determination of nitrites $\left(\mathrm{NO}_{2}\right)$ [23]. The chromophore is formed by the reaction between nitrite and Griess reagent. In brief, the brain homogenate was added to the Griess reagent to prepare the assay mixture and then $20 \mathrm{~min}$ incubation was given. The absorbance $(550 \mathrm{~nm})$ was taken against the $\mathrm{NO}_{2}$ standard (sodium nitrite) and $\mathrm{NO}_{2}$ concentration was represented as $\mu \mathrm{M} / \mathrm{mg}$ of protein.

\subsubsection{Tissue xanthine oxidase $(\mathrm{XO})$ activity}

The XO levels were estimated by the method described elsewhere [24]. The XO levels in the tissue were determined by the development of uric acid from xanthine, which leads to a rise in absorbance at $293 \mathrm{~nm}$. The absorbance was measured at $293 \mathrm{~nm}$, and one unit of XO activity at $37^{\circ} \mathrm{C}(\mathrm{pH} 7.5)$ was expressed as one $\mathrm{mmol}$ of uric acid $/ \mathrm{min}$.

\subsubsection{Total protein}

Lowry et al. method was used to determine the quantity of total protein in brain homogenates $(10 \% \mathrm{w} / \mathrm{v})$ [25].

\subsection{Estimation of Brain Infarction Size}

Immediately after 7 days of reperfusion, the rat brains were collected, after the decapitation and rinsed in cold saline. Subsequently, four coronal brain sections ( $2 \mathrm{~mm}$ thickness) were made with help of a steel brain matrix (Stoelting Co., USA). Further, the brain sections were incubated $\left(37^{\circ} \mathrm{C}\right)$ in a solution comprising phosphate-buffered saline (pH 7.4) and 2\% 2,3,5-triphenyl tetrazolium chloride (TTC: HiMedia, Mumbai, India) for $10 \mathrm{~min}$ and then placed overnight in the neutralbuffered formalin for fixation. Further, the brain sections stained with TTC were scanned in a high-resolution scanner (Scanjet-6100C/T, Hewlett-Packard, USA) [26], and the area of infarction was measured according to the newly developed semi-automated analysis of the TTC staining (SAT) software program guidelines for the infarct size quantification in rodent brain slices [27].

\subsection{Histopathological Evaluation}

The rats were sacrificed after reperfusion for 7 days and the brains were removed. Then, the brains were placed with formalin $(10 \% \mathrm{v} / \mathrm{v})$, fixed in paraffin wax, and cut into thick sections $(5 \mu \mathrm{m})$. Brain slices were stained using hematoxylin-eosin ( $\mathrm{H} \& \mathrm{E})$ and histopathological evaluations were carried out under a bright-field microscope (Leica DM 1000, Leica Microsystem, Germany). Further, neuronal density in the CA1 region of the hippocampus was estimated using the method proposed elsewhere [28]. The intact neurons were counted in the CA1 subfield of the hippocampus $\left(250 \mu \mathrm{m}^{2)}\right.$ in two different sections for each rat brain [29].

\subsection{Statistical Analysis}

The data are calculated for all samples (mean \pm S.E.M). One-way analysis of variance (ANOVA) followed by multiple comparisons of TukeyKramer's test was used to determine the significance level using GraphPad Prism (Version 5.0). Neurological deficit scores were assessed by the Kruskal-Wallis ANOVA test followed by Dunn's multiple comparisons test. Statistical differences were calculated at $\mathrm{p}<0.05$ as significant.

\section{RESULTS AND DISCUSSION}

Stroke, a predominant cause of mortality and physical impairment, has a shortage of curative therapies [30]. In this particular study, we used a global cerebral I/R injury experimental model that can simulate the human clinical stroke due to cardiac arrest or carotid artery occlusion. Global ischemia of more than 5 min of duration can lead to hippocampal neuronal damage and behavioral deficits [31].

\subsection{Neurobehavioral Functional Outcome Assessment}

\subsubsection{Effect of LIN on neurological deficits}

Cerebral $\mathrm{I} / \mathrm{R}$ injury resulted in a marked neurological deficit in the $\mathrm{I} / \mathrm{R}$ rats $(P<0.001)$ when compared with normal and sham rats. The LIN-treatment $(25,50$, and $100 \mathrm{mg} / \mathrm{kg})$ dose-dependently improved neurological deficit scores in rats [Figure 2a]. No ischemic neurological deficits were presented in the sham rats.

\subsubsection{LIN treatment attenuated I/R-induced behavioral deficits}

Upon I/R injury, rotarod test performance was significantly $(P<0.001)$ impaired in the $\mathrm{I} / \mathrm{R}$ rats when compared with normal and sham rats. The LIN-treatment $(25,50$, and $100 \mathrm{mg} / \mathrm{kg})$ markedly $(P<0.05$ and $P<0.001)$ improved the latency to fall from rotarod [Figure 2b].

As shown in Figure $2 \mathrm{c}$ and $\mathrm{d}$, the $\mathrm{I} / \mathrm{R}$ rats significantly reduced $\% \mathrm{OAE}$ $(P<0.001)$ and \%OT $(P<0.001)$ when compared with normal and sham rats. This indicated an anxiogenic effect of $\mathrm{I} / \mathrm{R}$ injury in rats. LIN-treated groups $(50$ and $100 \mathrm{mg} / \mathrm{kg})$ significantly $(P<0.001)$ improved \%OAE and \%OT. The lower dose of LIN (25 mg $/ \mathrm{kg})$ did not exhibit significant activity in the \%OAE and \%OT.

In the open-field paradigm, rats with $\mathrm{I} / \mathrm{R}$ injury showed marked alterations in exploratory behavior as evidenced by decreased ambulation, rearing, and grooming behavior when compared with the normal and sham rats. Whereas, this behavioral impairment was attenuated by LIN administration ( 50 and $100 \mathrm{mg} / \mathrm{kg}$ ) [Table 1]. The lower LIN (25 mg/kg) dose was non-significant.

The global model is mainly used to study stroke and its behavioral outcomes [32]. In this particular study, I/R rats showed anxiogenic behavior in the open-field paradigm and EPM tests compared to the LIN-treated groups. These findings are consistent with the earlier reports of I/R-injury induces anxiety in animals when subjected to a novel habitat $[5,33]$. LIN significantly improved these alterations in exploratory behavior, suggesting that LIN prevented I/R-induced anxiety development. Whereas, in the rotarod test, LIN improved motor coordination and balance. These investigations are in harmony with the earlier report of motor coordination and balance deficits induced by the global model of ischemia [34].

\subsection{Biochemical Estimation}

\subsubsection{Effect of LIN on LPO}

When subjected to I/R injury, rats significantly $(P<0.001)$ augmented LPO levels in brain homogenate when compared with the normal and sham rats dose-dependently reversed the alterations in LPO levels [Table 2].

Table 1: Effect of linalool (LIN) on open-field behavior in rats exposed to cerebral ischemia/reperfusion (I/R) injury.

\begin{tabular}{lccc} 
Groups & $\begin{array}{c}\text { Ambulations } \\
\text { (number) }\end{array}$ & $\begin{array}{c}\text { Rearings } \\
\text { (number) }\end{array}$ & $\begin{array}{c}\text { Groomings } \\
\text { (number) }\end{array}$ \\
Normal & $56.67 \pm 2.32$ & $28.50 \pm 0.99$ & $12.86 \pm 0.51$ \\
Sham & $51.67 \pm 3.20$ & $17.33 \pm 1.05^{* * *}$ & $9.71 \pm 0.29^{* * *}$ \\
I/R & $23.83 \pm 3.05^{* * *}$ & $9.167 \pm 1.19^{* * * *}$ & $7.14 \pm 0.55^{* * * *}$ \\
LIN+ I/R (25 mg/kg) & $16.67 \pm 1.86$ & $8.500 \pm 0.76$ & $8.14 \pm 0.51$ \\
LIN + I/R (50 mg/kg) & $38.17 \pm 2.24^{\#}$ & $17.83 \pm 1.25^{\# \#}$ & $9.14 \pm 0.34^{\#}$ \\
LIN + I/R (100 mg/kg) & $41.33 \pm 4.74^{\# \#}$ & $18.67 \pm 1.52^{\# \#}$ & $10.43 \pm 0.48^{\# \#}$ \\
\hline
\end{tabular}

Statistical analysis was carried out using One-way analysis of variance (ANOVA) followed by multiple comparison Tukey-Kramer's test. Values are represented as mean \pm SEM, $n=6$ and Statistical differences at ${ }^{* * *} \mathrm{P}<0.001$ from the normal group. Statistical differences at ${ }^{\#} P<0.05,{ }^{\#} P<0.01$, and ${ }^{\# \#} P<0.001$ from the $\mathrm{I} / \mathrm{R}$ group. 


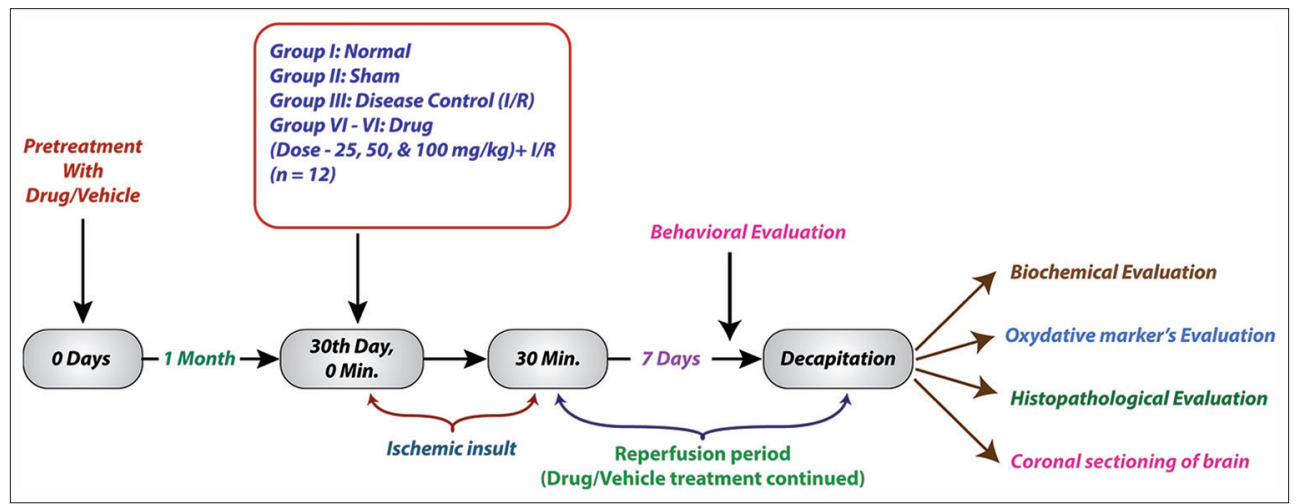

Figure 1: An experimental design representing drug/vehicle treatment, surgical process, and different evaluation parameters. I/R: Ischemia/reperfusion.
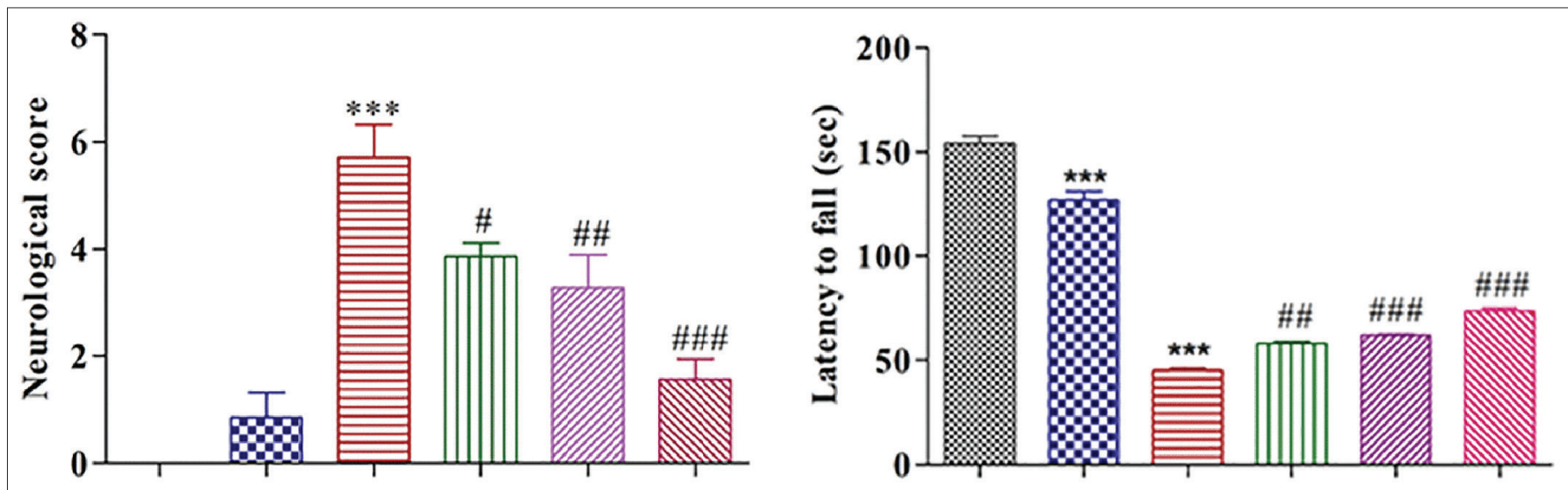

a

b
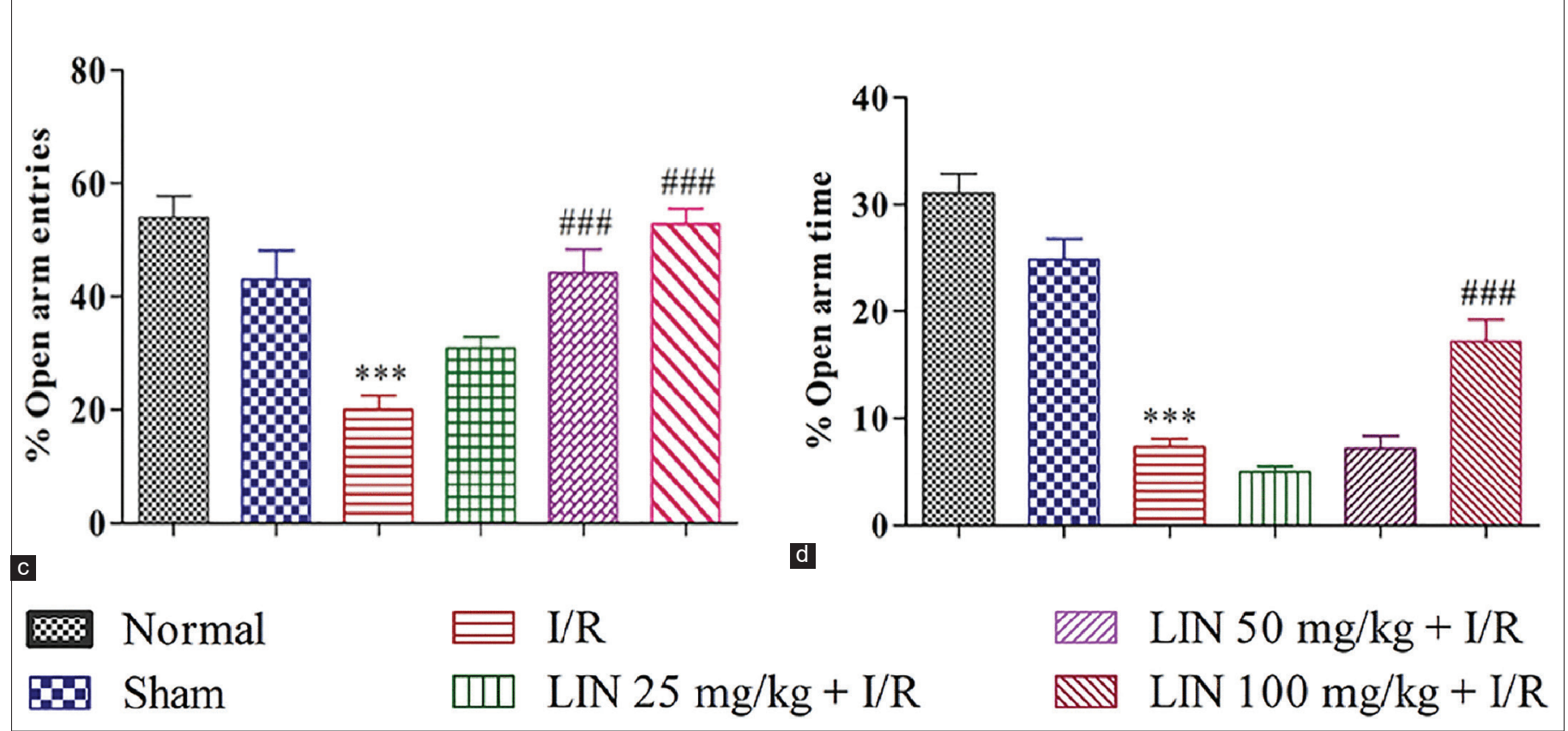

Figure 2: Effect of linalool (LIN) on functional neurobehavioral outcome measurements: (a) neurological deficit score (b) motor coordination (c and d) anxietyrelated behaviors 7 days after global model of ischemia in rats. The values are represented as mean \pm S.E.M., $\mathrm{n}=6 .{ }^{* * *} P<0.001$ vs. normal; ${ }^{\sharp} P<0.05,{ }^{\# \#} P<0.01$, and ${ }^{\#} P<0.001$ vs. I/R group. I/R: Ischemia/reperfusion. 
Table 2: Effect of linalool (LIN) on oxidative stress biomarkers (LPO, NO, XO, SOD, CAT, GSH, and total thiols) in global ischemia/reperfusion (I/R) -induced brain injury in rats.

\begin{tabular}{|c|c|c|c|c|c|c|c|}
\hline Groups & $\begin{array}{l}\mathrm{LPO}(\mathrm{nmol} / \mathrm{mg} \\
\text { of protein) }\end{array}$ & $\begin{array}{c}\mathrm{NO}(\mu \mathrm{mol} / \mathrm{mg} \\
\text { of protein) }\end{array}$ & $\begin{array}{c}\mathrm{XO}(\mathrm{U} / \mathrm{mg} \text { of } \\
\text { protein) }\end{array}$ & $\begin{array}{l}\text { SOD }(\mathrm{U} / \mathrm{mg} \\
\text { of protein) }\end{array}$ & $\begin{array}{l}\text { CAT (U/mg } \\
\text { of protein) }\end{array}$ & $\begin{array}{l}\text { GSH (nmol/mg } \\
\text { of protein) }\end{array}$ & $\begin{array}{l}\text { Total thiols }(\mu \mathrm{mol} / \mathrm{mg} \\
\text { of protein) }\end{array}$ \\
\hline Normal & $32.22 \pm 1.801$ & $0.05 \pm 0.004$ & $8.97 \pm 0.642$ & $181.1 \pm 8.294$ & $0.052 \pm 0.0007$ & $4.58 \pm 0.238$ & $13.46 \pm 0.427$ \\
\hline Sham & $96.78 \pm 7.594 * * *$ & $0.01 \pm 0.006^{*}$ & $15.23 \pm 0.275^{* * *}$ & $141.6 \pm 8.519 * * *$ & $0.034 \pm 0.0014 * * *$ & $3.15 \pm 0.131 * * *$ & $10.45 \pm 0.212 * * *$ \\
\hline $\mathrm{I} / \mathrm{R}$ & $160.5 \pm 9.383^{* * *}$ & $0.23 \pm 0.014 * * *$ & $25.21 \pm 0.883^{* * *}$ & $53.01 \pm 1.418^{* * *}$ & $0.009 \pm 0.0014 * * *$ & $2.22 \pm 0.073^{* * *}$ & $8.68 \pm 0.480 * * *$ \\
\hline $\begin{array}{l}\mathrm{LIN}+\mathrm{I} / \mathrm{R} \\
(25 \mathrm{mg} / \mathrm{kg})\end{array}$ & $138.6 \pm 1.687^{\#}$ & $0.19 \pm 0.011$ & $21.61 \pm 0.517^{\#}$ & $84.87 \pm 3.011^{\#}$ & $0.016 \pm 0.0016$ & $2.70 \pm 0.136$ & $10.39 \pm 0.316^{\#}$ \\
\hline $\begin{array}{l}\mathrm{LIN}+\mathrm{I} / \mathrm{R} \\
(100 \mathrm{mg} / \mathrm{kg})\end{array}$ & $81.13 \pm 2.175^{\# \# \# ~}$ & $0.06 \pm 0.012^{\# \# \#}$ & $10.93 \pm 0.971^{\# \# \#}$ & $140.1 \pm 13.03^{\# \#}$ & $0.043 \pm 0.0037^{\mathrm{\#}}$ & $4.01 \pm 0.327^{\# \#}$ & $12.52 \pm 0.152^{\# \#}$ \\
\hline
\end{tabular}

Statistical analysis was carried out using one-way analysis of variance (ANOVA) followed by multiple comparison Tukey-Kramer's test. Values are represented as mean \pm SEM, $\mathrm{n}=6$. Statistical differences at ${ }^{*} P<0.05$ and ${ }^{* * * *} P<0.001$ from the normal group. Statistical differences at ${ }^{\#} P<0.05$, ${ }^{\#} P<0.01$, and ${ }^{\# \#} P<0.001$ from the I/R group

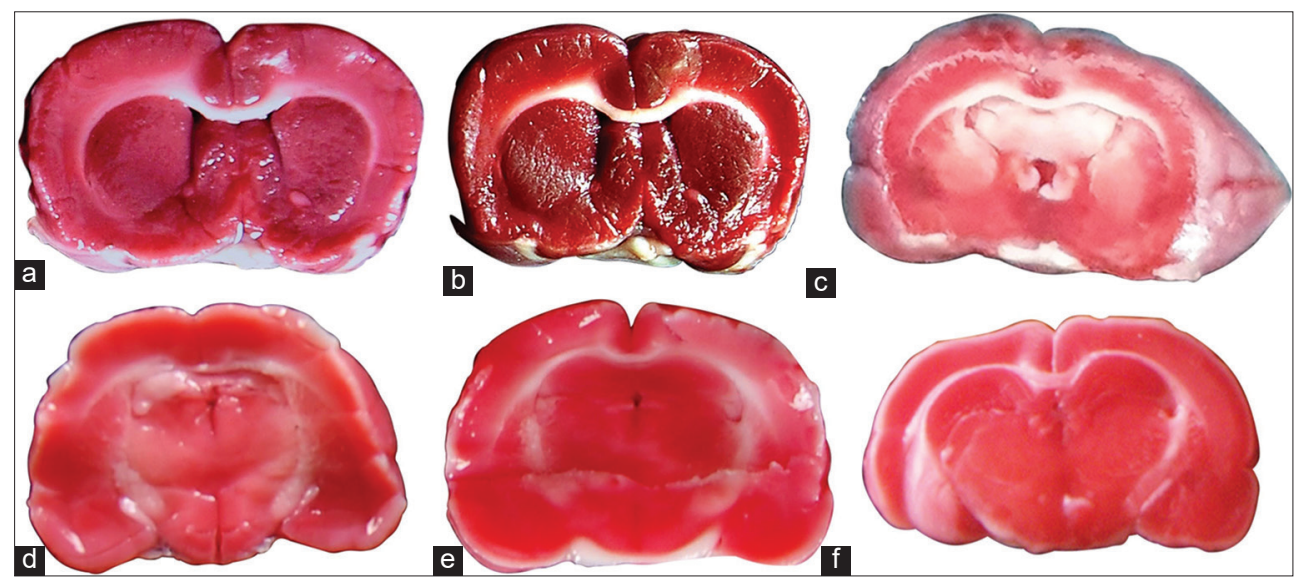

Figure 3: Brain coronal sections photographs of the rats stained with TTC. (a) Normal; (b) Sham group; (c) I/R group; (d-f) 25, 50, and 100 mg/kg + I/R of LIN, respectively. I/R: Ischemia/reperfusion; LIN: Linalool; TTC: 2,3,5-triphenyl tetrazolium chloride.

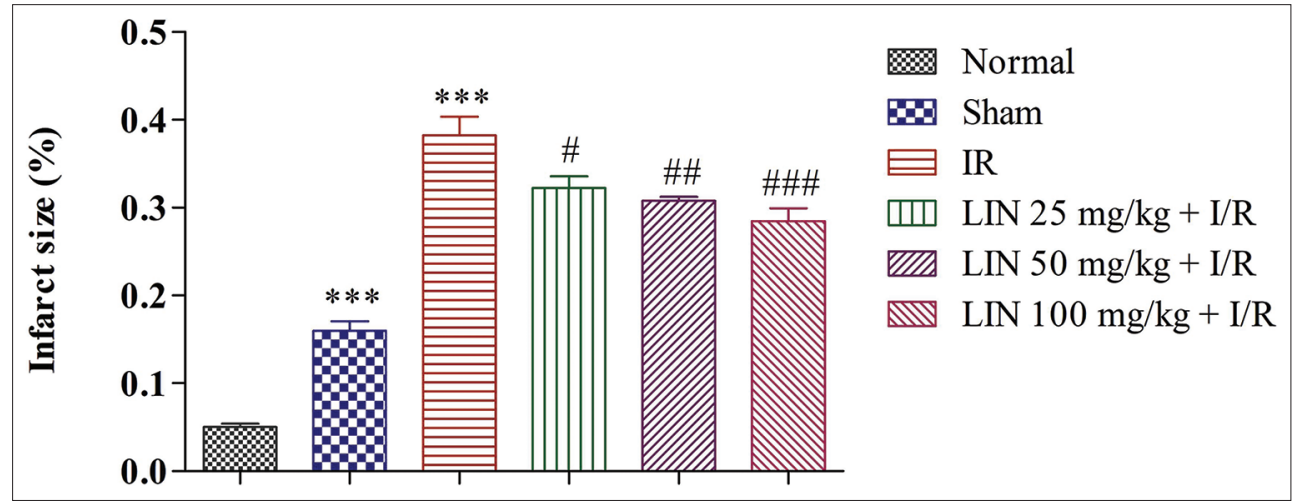

Figure 4: Cerebral infarct size (\%) 7 days after global model of ischemia in rats. The values are represented as mean \pm S.E.M., $\mathrm{n}=6$. ${ }^{* * *} P<0.001$ vs. normal;

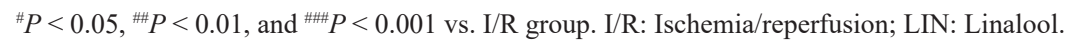

\subsubsection{Effect of LIN on oxidative stress biomarkers}

The I/R rats showed a marked decline in SOD $(P<0.001)$ and CAT $(P<0.001)$ levels when compared with normal and sham rats. LINtreatment prevented the reduction of SOD and CAT due to I/R injury [Table 2]. All three doses of LIN significantly restored SOD levels, whereas, in CAT, LIN (50 and $100 \mathrm{mg} / \mathrm{kg}$ ) revealed a significant increase in CAT levels compared to the $\mathrm{I} / \mathrm{R}$ rats.

Similarly, I/R injury caused a robust reduction in GSH and total thiols levels when compared with normal and sham rats. Rats with LIN treatment exhibited significant improvement in GSH and total thiol levels than I/R-treated rats. Further, the effect of LIN treatment on SOD was found to be dose-dependent. The lower LIN $(25 \mathrm{mg} / \mathrm{kg})$ dose produced insignificant improvement in CAT and GSH activities. These results directly evidenced the antioxidant potential of LIN [Table 2].

\subsubsection{Effect of LIN on NO metabolites}

NO contents in brain homogenates were markedly increased in the $\mathrm{I} / \mathrm{R}$ rats $(P<0.001)$ when compared with the normal and sham rats, 


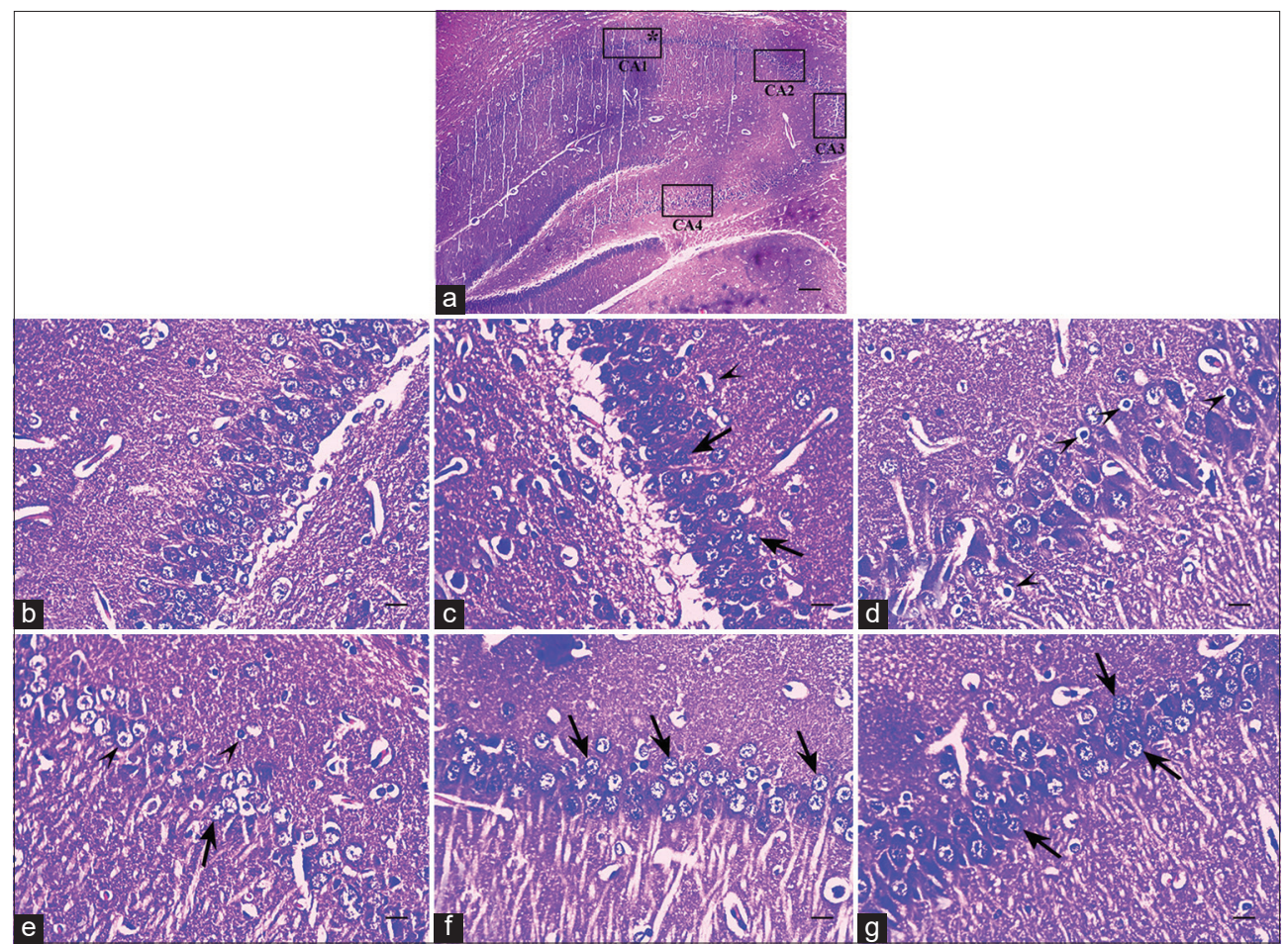

Figure 5: Photomicrographs of rat brain slices from various treatment groups stained with hemotoxylin and eosin. (a) Hippocampal region (5X); (b) normal; (c) sham; (d) I/R; (e-g) 25, 50, and $100 \mathrm{mg} / \mathrm{kg}+\mathrm{I} / \mathrm{R}$ of LIN, respectively. The asterisk designates the mid-view of CA1 regions at higher magnification. Arrowhead shows damaged neuronal cells and arrow indicates intact hippocampal CA1 pyramidal cells. The normal group (b) and the sham group (c) exhibited normal cerebrovasculature. I/R group (d) revealed neuronal damage as shown by pyramidal cells deprived of prominent nuclei and cerebrovasculature displaying lymphocytic proliferation and neuronal necrosis. Further, LIN-treated groups (e-g) showed neuroprotection as shown by several pyramidal cells with clear nuclei and nucleoli. Magnification: $\times 40$. Bar $=50 \mu \mathrm{m}(\mathrm{B}, \mathrm{C}, \mathrm{D}, \mathrm{E}$, and F); $\times 5$, bar $=500 \mu \mathrm{m}$ (a). I/R: Ischemia/reperfusion; LIN: Linalool.

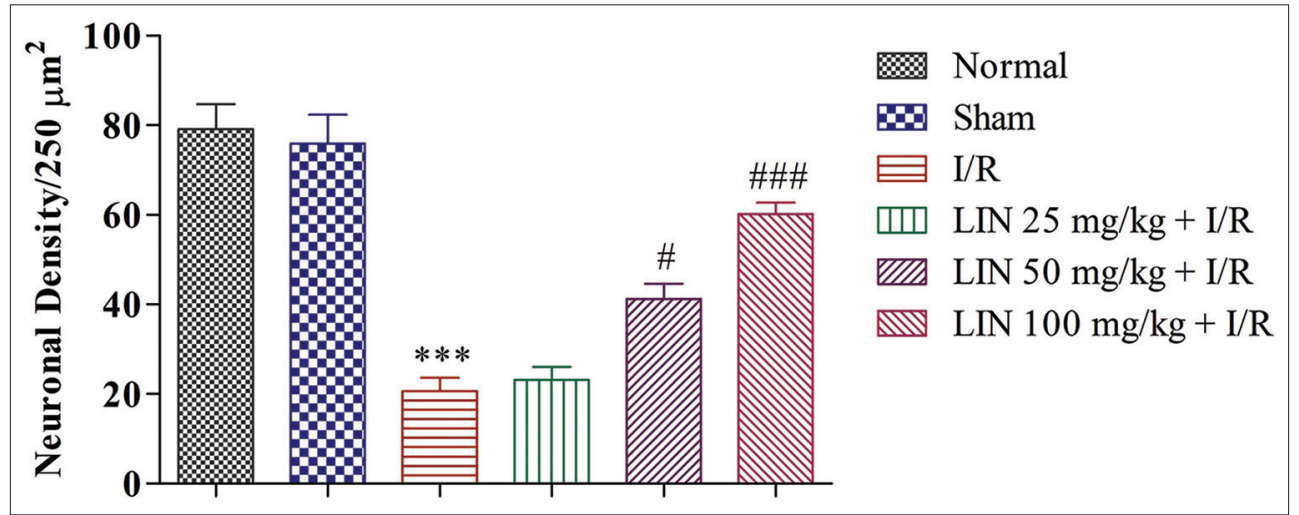

Figure 6: Effect of LIN on CA1 neuronal density. The values are represented as mean \pm S.E.M., $\mathrm{n}=6 .{ }^{* * *} P<0.001$ vs. normal; ${ }^{*} P<0.05$, and ${ }^{\# \# \# P} P<0.001$ vs. I/R. I/R: Ischemia/reperfusion; LIN: Linalool.

whereas LIN (50 and $100 \mathrm{mg} / \mathrm{kg}$ ) administration improved NO levels $(P<0.01$ and $P<0.001$, respectively) than $\mathrm{I} / \mathrm{R}$ rats [Table 2].

\subsubsection{Effect of LIN on tissue XO activity}

$\mathrm{I} / \mathrm{R}$ rats exhibited significantly increased XO activity $(P<0.001)$ when compared with normal and sham rats, whereas $\operatorname{LIN}(25,50$, and $100 \mathrm{mg} / \mathrm{kg}$ ) treatment dose-dependently decreased XO activity than I/R-treated rats [Table 2].

Sizable evidence suggests that ROS plays a pivotal role in the pathophysiology of I/R-provoked oxi and nitro-dative stress in the brain $[5,6]$. SOD and CAT are well-investigated antioxidant enzymes that coact against ROS and limit ROS-induced damage. SOD converts $\mathrm{O}_{2}^{--}$to $\mathrm{H}_{2} \mathrm{O}_{2}$ and persuades a defensive role against oxidative stress. Subsequently, CAT decomposed $\mathrm{H}_{2} \mathrm{O}_{2}$ into the water $[6,33,35]$. In addition, the intensity of oxidative damage was assessed by the estimation of GSH and T-SH in the brain tissue. Glutathione, a central antioxidant defense component of cells, directly scavenges ROS and/or works as a substrate for several peroxidases. Further, I/R insult significantly reduces the levels of GSH and T-SH [6,35]. In this particular study, LIN-treatment significantly re-established antioxidant enzymes (SOD and CAT) and enhanced non-enzymatic defenses (GSH and T-SH), thus, improved oxidative 
defense and showed neuroprotective potential. These findings are consistent with the previous reports on the neuroprotective effect of herbal isolates such as solasodine [6] and glabridin [36], exhibiting modulations of antioxidant enzymes such as SOD and GSH.

Further, ROS generated due to $\mathrm{I} / \mathrm{R}$ insult produces injury to the cellular components such as protein, lipids, and nucleic acid [6]. Excessive generation of ROS exacerbates the LPO process that leads to malondialdehyde (MDA) development as an end product. TBRAS is produced due to the reaction between MDA and TBA. Thus, MDA was measured using the TBARS assay to evaluate the quantity of LPO. Moreover, xanthine dehydrogenase undergoes irreversible proteolytic conversion to $\mathrm{XO}$ during ischemia. $\mathrm{XO}$ is a significant criterion in the generation of $\mathrm{O}_{2}^{-}$after acute $\mathrm{I} / \mathrm{R}$ injury and produces detrimental effects upon neurons. [6,37]. Such findings are consistent with our results where a significant increase in LPO, NO, and XO content in rat brains after I/R insult. Interestingly, we found that LIN-treatment improved the levels of LPO, NO, and XO in the rat brain.

\subsection{Estimation of Infarct Size in Rat Brain}

Figure 3 depicts the coronal section of the rat brain for all experimental groups. The normal and sham group did not show ischemic damage [Figure $3 \mathrm{a}$ and $\mathrm{b}$ ], whereas marked neuronal infarction (pale yellow to white-colored tissue) was detected in the I/R group [Figure $3 \mathrm{c}$ ]. Furthermore, the rats with LIN-treatment exhibited a predominantly red-colored tissue demonstrating neuroprotection [Figure 3d-f].

To further confirm neuroprotection by LIN, we have estimated neuronal infarct size $(\%)$. I/R rats showed significant $(P<0.001)$ neuronal infarction than the normal and sham rats. Whereas, the treatment with $\operatorname{LIN}(25,50$, and $100 \mathrm{mg} / \mathrm{kg})$ dose-dependently reduced the neuronal infraction that confirmed its potential neuroprotective action [Figure 4].

\subsection{Histopathological Evaluation}

Figure 5 a shows the dentate gyrus of the rat brain, whereas other plates of Figure 5b-g demonstrate the subfield of the hippocampal CA1 region from the studied animal groups. As evident from Figure 5, the $\mathrm{I} / \mathrm{R}$ group revealed damaged and clustered neurons in the hippocampal CA1 region which specifies lymphocytic proliferation and neuronal necrosis [Figure 5d] compared to the normal [Figure 5b] and sham [Figure 5c] rats. In contrast, LIN-treated [Figure 5e-g] groups exhibited a progressive abundance of intact globular and well-stained neurons when compared with the $\mathrm{I} / \mathrm{R}$ rats that also confirmed the neuroprotective potential of LIN-treatment.

Further, the estimation of neuronal density in the hippocampal CA1 subfields of experimental groups showed that $\mathrm{I} / \mathrm{R}$ insult resulted in a significant decrease in neuronal damage $(P<0.001)$ when compared with the normal and sham rats. Whereas, LIN-treatment with $50 \mathrm{mg} / \mathrm{kg}(P<0.05)$ and $100 \mathrm{mg} / \mathrm{kg}(P<0.001)$ exhibited a significant increase in the pyramidal neuron density than the $\mathrm{I} / \mathrm{R}$ rats proved its neuroprotective potential [Figure 6].

Histological and brain infarct size evaluations of rat brain coronal sections were performed to confirm the neuroprotective potential of LIN. It is well-documented that TTC imparts deep red color to the viable cells of the tissue, whereas the infarcted cells in the ischemic zone remain unstained pale yellow to white [26,31]. Upon I/R insult, we found a marked increase in brain infarct size (\%) in the $I / R$ rats, whereas LIN treatment markedly reduced the infarct size (\%) which is in harmony with previous studies on different animal models [37,38].
Several studies reported that transient cerebral $\mathrm{I} / \mathrm{R}$ insult provokes hippocampal CA1 neuronal damage in the rat brain [4-6]. A similar pattern was observed in the I/R rats, in which, I/R-injury provoked marked damage as indicated by distorted cerebrovasculature and damaged hippocampal CA1 pyramidal neurons in the rat brain. On the contrary, LIN-treatment restored neuronal damage in rats. Further, this neuron favoring activity was confirmed by neuronal density analysis in the CA1 region which revealed that LIN treatment (50 and 100 $\mathrm{mg} / \mathrm{kg}$ ) was efficacious in preserving hippocampal CA1 pyramidal neurons. These activities of LIN treatment on cerebral infarction and hippocampal CA1 neuron protection are in agreement with the previous studies that stated the neuroprotection of alpha-linolenic acid in ischemic stroke $[39,40]$. The neuroprotective action of LIN after cerebral I/R injury could be attributed to its antioxidant potential.

\section{CONCLUSION}

These results propose a potential neuroprotective role of LIN against the transient cerebral $\mathrm{I} / \mathrm{R}$-induced brain injury in experimental rats. The study findings proposed that LIN modulates intracellular antioxidants defense mechanism and thereby protects I/R-induced oxidative stress. It should be recognized that potent antioxidants proved neuroprotective in experimental models, have shown limited clinical efficacy except for edaravone. This could be because of species variation in oxidative stress-induced pathophysiology pathways that produce a differential response to antioxidants in various species. Further, this species-dependent response is attributed to the dosage and therapeutic regimens as well. Therefore, an in-depth evaluation of the window of opportunity in different stroke models should be assured when translating the present findings.

\section{AUTHOR CONTRIBUTIONS}

All authors made substantial contributions to conception and design, acquisition of data, or analysis and interpretation of data; took part in drafting the article or revising it critically for important intellectual content; agreed to submit to the current journal; gave final approval of the version to be published; and agree to be accountable for all aspects of the work. All the authors are eligible to be an author as per the international committee of medical journal editors (ICMJE) requirements/guidelines.

\section{FUNDING}

There is no funding to report.

\section{CONFLICTS OF INTEREST}

The authors report no financial or any other conflicts of interest in this work.

\section{PUBLISHER'S NOTE}

This journal remains neutral with regard to jurisdictional claims in published institutional affiliation.

\section{REFERENCES}

1. Jayaraj RL, Azimullah S, Beiram R, Jalal FY, Rosenberg GA. Neuroinflammation: Friend and foe for ischemic stroke. J Neuroinflammation 2019;16:142.

2. Gorelick PB. The global burden of stroke: Persistent and disabling. Lancet Neurol 2019;18:417-8.

3. Hackam DG, Spence JD. Antiplatelet therapy in ischemic stroke and 
transient ischemic attack. Stroke 2019;50:773-8.

4. Zhang R, Liu C, Liu X, Guo Y. Protective effect of Spatholobus suberectus on brain tissues in cerebral ischemia. Am J Transl Res 2016;8:3963-9.

5. Lu Q, Tucker D, Dong Y, Zhao N, Zhang Q. Neuroprotective and functional improvement effects of methylene blue in global cerebral ischemia. Mol Neurobiol 2016;53:5344-55.

6. Sharma T, Airao V, Panara N, Vaishnav D, Ranpariya V, Sheth N, et al. Solasodine protects rat brain against ischemia/reperfusion injury through its antioxidant activity. Eur J Pharmacol 2014;725:40-6.

7. Watanabe K, Tanaka M, Yuki S, Hirai M, Yamamoto Y. How is edaravone effective against acute ischemic stroke and amyotrophic lateral sclerosis? J Clin Biochem Nutr 2018;62:20-38.

8. Vivien D, Gauberti M, Montagne A, Defer G, Touze E. Impact of tissue plasminogen activator on the neurovascular unit: From clinical data to experimental evidence. J Cereb Blood Flow Metab 2011;31:2119-34.

9. Kumar GP, Khanum F. Neuroprotective potential of phytochemicals. Pharmacogn Rev 2012;6:81-90.

10. Batista PA, Werner MF, Oliveira EC, Burgos L, Pereira P, Brum LF, et al. The antinociceptive effect of (-)-linalool in models of chronic inflammatory and neuropathic hypersensitivity in mice. J Pain 2010;11:1222-9.

11. Celik S, Ozkaya A. Effects of intraperitoneally administered lipoic acid, vitamin E, and linalool on the level of total lipid and fatty acids in guinea pig brain with oxidative stress induced by $\mathrm{H}_{2} \mathrm{O}_{2}$. J Biochem Mol Biol 2002;35:547-52.

12. Mehri S, Meshki MA, Hosseinzadeh H. Linalool as a neuroprotective agent against acrylamide-induced neurotoxicity in Wistar rats. Drug Chem Toxicol 2015;38:162-6.

13. Mughal MH. Linalool: A mechanistic treatise. J Nutr Food Res Technol 2019;2:1-5.

14. Farbiszewski R, Bielawski K, Bielawska A, Sobaniec W. Spermine protects in vivo the antioxidant enzymes in transiently hypoperfused rat brain. Acta Neurobiol Exp (Wars) 1995;55:253-8.

15. Lawner P, Laurent J, Simeone F, Fink E, Rubin E. Attenuation of ischemic brain edema by pentobarbital after carotid ligation in the gerbil. Stroke 1979;10:644-7.

16. Rogers DC, Campbell CA, Stretton JL, Mackay KB. Correlation between motor impairment and infarct volume after permanent and transient middle cerebral artery occlusion in the rat. Stroke 1997;28:2060-5.

17. Bronstein PM. Repeated trials with the albino rat in the open field as a function of age and deprivation. J Comp Physiol Psychol 1972;81:84-93.

18. Soares RO, Oliveira LM, Marchini JS, Antunes-Rodrigues J, Elias LL, Almeida SS. Effects of early protein malnutrition and environmental stimulation on behavioral and biochemical parameters in rats submitted to the elevated plus-maze test. Nutr Neurosci 2013;16:104-12.

19. Braughler JM, Chase RL, Pregenzer JF. Oxidation of ferrous iron during peroxidation of lipid substrates. Biochim Biophys Acta 1987;921:457-64.

20. Misra HP, Fridovich I. The role of superoxide anion in the autoxidation of epinephrine and a simple assay for superoxide dismutase. J Biol Chem 1972;247:3170-5.

21. Claiborne A. Catalase activity. In: Greenwald RA, editors. CRC Hand Book of Methods for Oxygen Radical Research. Boca Raton, Florida: CRC Press; 1985. p. 283-4.

22. Sedlak J, Lindsay RH. Estimation of total, protein-bound, and nonprotein sulfhydryl groups in tissue with Ellman's reagent. Anal Biochem 1968;25:192-205.

23. Miranda KM, Espey MG, Wink DA. A rapid, simple spectrophotometric method for simultaneous detection of nitrate and nitrite. Nitric Oxide 2001;5:62-71.
24. Prajda N, Weber G. Malignant transformation-linked imbalance: Decreased xanthine oxidase activity in hepatomas. FEBS Lett 1975;59:245-9.

25. Lowry OH, Rosebrough NJ, Farr AL, Randall RJ. Protein measurement with the Folin phenol reagent. J Biol Chem 1951;93:265-75.

26. Isayama K, Pitts LH, Nishimura MC. Evaluation of 2,3,5-triphenyltetrazolium chloride staining to delineate rat brain infarcts. Stroke 1991;22:1394-8.

27. Shi XF, Ai H, Lu W, Cai F. SAT: Free software for the semi-automated analysis of rodent brain sections with 2,3,5-triphenyltetrazolium chloride staining. Front Neurosci 2019;13:102.

28. Buchan A, Li H, Pulsinelli WA. The N-methyl-D-aspartate antagonist, MK-801, fails to protect against neuronal damage caused by transient, severe forebrain ischemia in adult rats. J Neurosci 1991;11:1049-56.

29. Sharma T, Airao V, Buch P, Vaishnav D, Parmar S. Sesamol protects hippocampal CA1 neurons and reduces neuronal infarction in global model of cerebral ischemia in rats. PharmaNutrition 2020;2020:100217.

30. Balch MH, Nimjee SM, Rink C, Hannawi Y. Beyond the brain: The systemic pathophysiological response to acute ischemic stroke. J Stroke 2020;22:159-72.

31. Shri R, Singh Bora K. Neuroprotective effect of methanolic extracts of Allium cepa on ischemia and reperfusion-induced cerebral injury. Fitoterapia 2008;79:86-96.

32. Durukan A, Strbian D, Tatlisumak T. Rodent models of ischemic stroke: A useful tool for stroke drug development. Curr Pharm Des 2008;14:359-70.

33. Yanpallewar SU, Rai S, Kumar M, Acharya SB. Evaluation of antioxidant and neuroprotective effect of Ocimum sanctum on transient cerebral ischemia and long-term cerebral hypoperfusion. Pharmacol Biochem Behav 2004;79:155-64.

34. Park SI, Jang DK, Han YM, Sunwoo YY, Park MS, Chung YA, et al. Effect of combination therapy with sodium ozagrel and Panax ginseng on transient cerebral ischemia model in rats. J Biomed Biotechnol 2010;2010:893401.

35. Buch P, Patel V, Ranpariya V, Sheth N, Parmar S. Neuroprotective activity of Cymbopogon martini against cerebral ischemia/ reperfusion-induced oxidative stress in rats. J Ethnopharmacol 2012;142:35-40.

36. Yu XQ, Xue CC, Zhou ZW, Li CG, Du YM, Liang J, et al. In vitro and in vivo neuroprotective effect and mechanisms of glabridin, a major active isoflavan from Glycyrrhiza glabra (licorice). Life Sci 2008;82:68-78.

37. Bora KS, Sharma A. Evaluation of antioxidant and cerebroprotective effect of Medicago sativa Linn. against ischemia and reperfusion insult. Evid Based Complement Altern Med 2011;2011:792167.

38. Malik ZA, Singh M, Sharma PL. Neuroprotective effect of Momordica charantia in global cerebral ischemia and reperfusion induced neuronal damage in diabetic mice. J Ethnopharmacol 2011;133:729-34

39. Nguemeni C, Delplanque B, Rovere C, Simon-Rousseau N, Gandin C, Agnani G, et al. Dietary supplementation of alphalinolenic acid in an enriched rapeseed oil diet protects from stroke. Pharmacol Res 2010;61:226-33.

40. Bourourou M, Heurteaux C, Blondeau N. Alpha-linolenic acid given as enteral or parenteral nutritional intervention against sensorimotor and cognitive deficits in a mouse model of ischemic stroke. Neuropharmacology 2016;108:60-72.

\footnotetext{
How to cite this article:

Airao V, Buch P, Sharma T, Vaishnav D, Parmar S. Linalool protects

hippocampal CA1 neurons and improves functional outcomes following

experimental ischemia/reperfusion in rats. J App Biol Biotech.

2021;9(2):174-181. DOI: 10.7324/JABB.2021.9218
} 